\title{
ANALISIS POTENSI DAYA DUKUNG LAHAN UNTUK PENGEMBANGAN SAPI POTONG DI KAWASAN PAKAKAAN KABUPATEN MINAHASA
}

\author{
H. A. L. Tiwow*, V. V. J. Panelewen, Arie Dp. Mirah \\ Program Studi Agronomi, Pascasarjana Universitas Sam Ratulangi, Manado
}

\begin{abstract}
ABSTRAK
Penelitian ini telah dilaksanakan di Kawasan "Pakakaan" Kabupaten Minahasa pada 2 Februari 2014 hingga 5 April 2014. Tujuan penelitian ini yaitu mengidentifikasi dan menghitung daya dukung lahan sebagai sumber hijauan pakan sapi potong, Metode analisis yang di gunakan dalam penelitian ini adalah deskriptif analisis, dimana pemilihan lokasi penelitian dilakukan menurut metode purposive sampling, dengan pertimbangan wilayah ini merupakan kawasan agropolitan di mana salah satu komoditi unggulannya adalah sapi potong. Data yang dikumpulkan meliputi data sekunder. Data sekunder terkait dengan topik penelitian bersumber dari: a) BPS Kabupaten Minahasa, b) Dinas Pertanian Peternakan dan Perkebunan Kabupaten Minahasa, c) bahan bacaan dan hasil penelitian yang di terbitkan oleh lembaga resmi. Data kemudian diolah dan dianalisis melalui perhitungan Indeks Daya Dukung lahan. Kawasan Pakakaan ini memiliki luas sebesar $\pm 356,68 \mathrm{~km}^{2}$, tersebar pada 10 wilayah kecamatan. Pada tahun 2013 penduduk di kawasan ini sebesar 106.270 jiwa, dengan tingkat kepadatan penduduk

per kecamatan sebesar rata-rata 298 jiwa/Km2. (Dinas Pertanian Peternakan dan Perkebunan 2014). Luas lahan di kawasan ini sebesar 32.010 Ha, dengan jumlah rumah tangga 27.264 KK maka kepadatan agraris sebesar 1,77 Ha/KK. Populasi sapi pada Tahun 2013 sebanyak 10.581 ekor, jumlah peternak sapi 4.038 org, berarti pemilikan sapi rata-rata 2,62 ekor/org dan kepadatan ternak sapi sebesar 29,67 ekor/Km2. Hasil penelitian menunjukkan bahwa dengan luas lahan sebesar $32.010 \mathrm{Ha}$ akan dapat menghasilkan hijuan rumput ternak sapi sejumlah 11.541 ton/tahun. Sedangkan jerami dapat dihasilkan sebesar 123.934 ton per tahun. Ini berarti
\end{abstract}

\footnotetext{
* Korespondesi (corresponding author):
}

Email: herman_tiwow@yahoo.com potensi ketersediaan pakan sebanyak 135.484 ton rata-rata pertahun. Dari hasil analisis satuan ternak, populasi ternak sapi sejumlah 8.040 ST, dimana daya tampung ternak sapi sebanyak 118.846 ST/tahun, apabila dikurangi dengan populasi ternak sapi yang ada maka potensi pengembangan sebesar 108.740 ST/tahun. Kesimpulan sebagai berikut; Indeks Daya Dukung (IDD) Lahan, di Kawasan Pakakaan berada dalam kategori "aman" dengan nilai > 2 untuk pengembangan sapi potong,

Kata kunci : sapi potong, satuan ternak, indeks daya dukung.

\section{ABSTRACT}

\section{ANALYSIS OF LAND CARRYING CAPACITY AND ITS POTENCY FOR BEEF CATTLE DEVELOPMENT IN PAKAKAAN MINAHASA REGENCY.} This study has been conducted in The Pakakaan ", Minahasa Regency on February $2^{\text {nd }}-$ April $5^{\text {th }}$ 2014. The study aimed to: identify and calculate the carrying capacity of the land as a source of forage feed. Method of analysis that used in this study was descriptive analysis, where the research locations was selected by purposive sampling method, with consideration that the area is agropolitan region, in which beef cattle as the main commodity. Data collected were included secondary data. Secondary data were from: a) Minahasa Statistics Center Bureau, b) the Department of Agriculture, Livestock and Agriculture Service of Minahasa, c) reading material and results of research published by official agencies. The source of the data that is; a) the stakeholders (farmers / ranchers, merchants, butcher, retailers and consumers of 
beef) b) experts / specialists (college / Toma) c) SKPD and related agency in Minahasa. The data was then processed and analyzed through the calculation land capacity index. Pakakaan is a region defined by the government Minahasa as an Agropolitan region where its main commodity is beef cattle. This region has an area extent of about $356.68 \mathrm{~km} 2$, which spread in 10 sub-districts. By 2013 the population in the region were 106.270 inhabitants, the population density per districts amounted to an average 298 people $/ \mathrm{km} 2$ (Department of Agriculture and Minahasan Livestock and Agriculture Service, 2014). The land area extent in the region was 32.010 hectares, with the total number of agricultural households $(\mathrm{HH})$ were 27.264 , the density was $1.77 \mathrm{ha} / \mathrm{HH}$. Cattle population in the year 2013 as many as 10.581 heads, thenumber of cattle farmers were 4.038, which means the averageof cattle ownership was 2.62 heads/farmer, and the beef cattle density was $29.67 \mathrm{heads} / \mathrm{km} 2$. The results showed that with a land area of 32.010 hectares will be able to produce forage for cattle in the amount of 11.541 tonnes per year, while the roughage can be generated by 123.934 tonnes per year. These means that the average of feed potential availability as much as 135.484 tonnes per year. Based on the livestock unit analysis, the animal unit (AU)of cattle population was 8.040 AU, in which the total capacity of cattle was $118.846 \mathrm{AU} / \mathrm{year}$, when it subtracted by the recent total cattle population there, hence the development potential was 108.740 AU per year. It is concluded:1)the land carrying capacity index (CCI) for the development of beef cattle in the Pakakaan region was in the category of "safe" with a value of $>2$,

Keywords : beef cattle, animal unit, capability index.

\section{PENDAHULUAN}

Pertumbuhan populasi sapi potong secara nasional sampai saat ini belum mampu mengimbangi pertumbuhan jumlah pemotongan. Sehingga berakibat adanya kelebihan permintaan dibandingkan penyediaan. Dalam rangka menanggulangi masalah tersebut, telah ditempuh berbagai upaya, antara lain kebijakan impor dan program swasembada daging sapi. Namun kedua kebijakan tersebut menimbulkan berbagai permasalahan seperti menghambat perkembangan populasi ternak sapi lokal. memicu terjadinya penjualan sapi betina produktif dan sapi muda dan melambungnya harga sapi di pasaran. Oleh karena itu, diperlukan terobosan dan inovasi program yang diharapkan dapat menanggulangi hal-hal tersebut.

Salah satu alternatif program yang dapat di kembangkan yaitu pembangunan kawasan sentra produksi sapi potong, yang digerakkan oleh kesisteman agribisnis dengan pendekatan LEISA, zero west. Kabupaten Minahasa, merupakan salah satu Kabupaten di Propinsi Sulawesi Utara yang memiliki luas lahan perkebunan/ seluas 53.992,82 ha dan penggunaan pertanian lahan kering 12.239,24 ha, dengan ketinggian sekitar100-1000m dari permukaan laut (Dinas Pertanian Kabupaten Minahasa 2014), memiliki potensi yang cukup besar untuk pengembangan kawasan sentra produksi ternak sapi potong. Sejak tahun 2007 di Kabupaten Minahasa telah dibangun Kawasan Agropolitan PAKAKAAN, dimana salah satu komoditi unggulannya 
yaitu sapi potong. Sampai saat ini Kawasan PAKAKAAN ini belum ada pengembangan sapi potong, bahkan infrastruktur yang telah terbangun seperti kandang sapi, RPH dan industri pupuk organik dari kotoran sapi hanya diterlantarkan.

\section{MATERI DAN METODE PENELITIAN}

Penelitian ini telah dilaksanakan di Kawasan "Pakakaan" Kabupaten Minahasa mulai tanggal 2 Februari 2014 sampai dengan 5 April 2014. Metode pemilihan lokasi pada penelitian ini menggunakan purposive sampling (sengaja) yaitu, Kawasan "Pakakaan" di Kabupaten Minahasa dengan pertimbangan, wilayah ini merupakan kawasan agropolitan dimana salah satu komoditi unggulannya adalah sapi potong.

Data yang digunakan dalam penelitian ini adalah data sekunder. Data sekunder diperoleh dari Badan Pusat Statistik (BPS) Kabupaten Minahasa, Dinas Pertanian Peternakan dan Perkebunan Kabupaten Minahasa, Bappeda
Kabupaten Minahasa dan Badan Penyuluh Pertanian/Peternakan tingkat kecamatan, serta bahan bacaan dan hasil penelitian yang diterbitkan oleh lembaga resmi.

Metode analisis data yang digunakan dalam penelitian ini adalah deskriptif analitis. Metode ini dilakukan dengan mengumpulkan data dari berbagai sumber, kemudian disusun dan dianalisis menjadi informasi untuk dijelaskan (Irianto dan Mardikanto, 2010).

Parameter yang di amati :

1. Potensi Limbah (Jerami)

$$
\begin{aligned}
= & (\text { ps } \times 0,4)+(\text { pi } 3 \times 0,4)+ \\
& \text { us } \times 3 \times 0,5)+\left(\begin{array}{ll}
\mathrm{kdx} 3 \times 0,55
\end{array}\right) \\
& +\{(\mathrm{kh}+\mathrm{kt}) \times 2 \times 0,55\}+ \\
& \{(\mathrm{uj} \times 0,2516)+(\mathrm{uk} \times 0,25 / 4) 1 \\
& \times 0,65
\end{aligned}
$$

\section{Keterangan:} ps=padi sawah, $\mathrm{pl}=$ padi ladang, jg=jagung, $\mathrm{kd}=$ kedelai, kh=kacang hijau, $\mathrm{kt}=\mathrm{kacang}$ tanah, $\mathrm{uj}=\mathrm{ubi}$ jalar, uk=ubi kayu. 
2. Potensi Hijauan Alami

$$
\begin{aligned}
= & \{(\text { Pkarang x 0,53 x 2) }+ \\
& (\text { Teg. + huma }+ \text { lad }+ \\
& \text { kebun + L.bera }) \times 2,875) \\
& +(\text { Penggern } \times 0,75 »+ \\
& (\text { HrytxO,6 })+(\text { Lain x } 0,75) \\
& +(\text { Lkld x 10) }+(\text { Lckh x } \\
& 5)\} \times 0,5
\end{aligned}
$$

Keterangan:

Pkarang=pekarangan,

teg=tegalan,

lad=ladang,

L.bera=lahan beru,

Penggem=penggembalaan,

Hryt= hutan rakyak,

Lain=lain-lain,

Lkld=luas tanaman kelapa dalam,

Lckh=Iuas tanaman cengkeh.

3. Kebutuhan Pakan Minimum,

Sumanto dan Juarini (2006)

$\mathrm{K}=2,5 \% \times 50 \% \times 365 \times 250 \mathrm{Kg}$

$=1.14$ ton $\mathrm{BK} /$ tahun $/ \mathrm{ST}$

Keterangan:

$\mathrm{K}=$ Kebutuhan pakan minimum untuk 1 ST dalam ton bahan kering tercerna selama satu tahun.

$2,5 \%=$ Kebutuhan minmum jumlah ransum hijauan pakan (bahan kering) terhadap berat badan.

$50 \%=$ Nilai rata-rata daya cerna berbagai jenis tanaman

$365=$ Jumlah hari dalam satu tahun

$250 \mathrm{~kg}=$ Berat hidup 1 ST (keadaan dapat berubah sesuai kondisi ternak pada setiap wilayah).

4. Daya Dukung Pakan Hijauan, Sumanto dan Juarini (2006)

Daya Dukung $(\mathrm{ST})=$

Produksi Bahan Kering (kg)

KBK Sapi Dewasa (kg/ST)

5. Indeks Daya Dukung (IDD), Ashari et al. (1995)

IDD Hijauan =

$$
\frac{\text { TPBK }(\mathrm{kg})}{\text { JPR (ST)x KBK Sapi Dewasa }(\mathrm{kg} / \mathrm{ST})}
$$

Keterangan:

TPBK = total produksi bahan kering

JPR = Jumlah

populasi ruminansia

$\mathrm{KBK}=$ kebutuhan bahan kering 
Berdasarkan nilai indeks daya dukung diperoleh kriteria status daya dukung hijauan. Indeks daya dukung mencerminkan tingkat keamanan pakan pada suatu wilayah, untuk mendukung kehidupan ternak yang berada di atasnya. Kriteria "aman" ditandai dengan indeks daya dukung (IDD) $>2 ; \quad$ IDD $<1,5-2$ menunjukkan kriteria "rawan"; IDD $<$ 1-1,5 menunjukkan kriteria "kritis" dan IDD $<1$ menunjukkan kriteria “sangat kritis" (Ashari et.al., 1995).

\section{HASIL DAN PEMBAHASAN}

Produksi Rumput
Menurut Sajimin et.al. (2000), pengaruh iklim dan kondisi ekologi sangat menentukan ketersediaan hijauan sebagai pakan ternak di suatu wilayah sehingga hijauan makanan ternak tidak dapat tersedia sepanjang tahun. Pada musim penghujan produksi hijauan berlimpah dan sebaliknya di musim kemarau hijauan sebagai sumber pakan ternak jarang diperoleh. Ketersediaan hijauan secara kuantitas dan kualitas juga dipengaruhi oleh pembatasan lahan tanaman pakan karena penggunaan lahan untuk tanaman pakan masih bersaing dengan tanaman pangan.

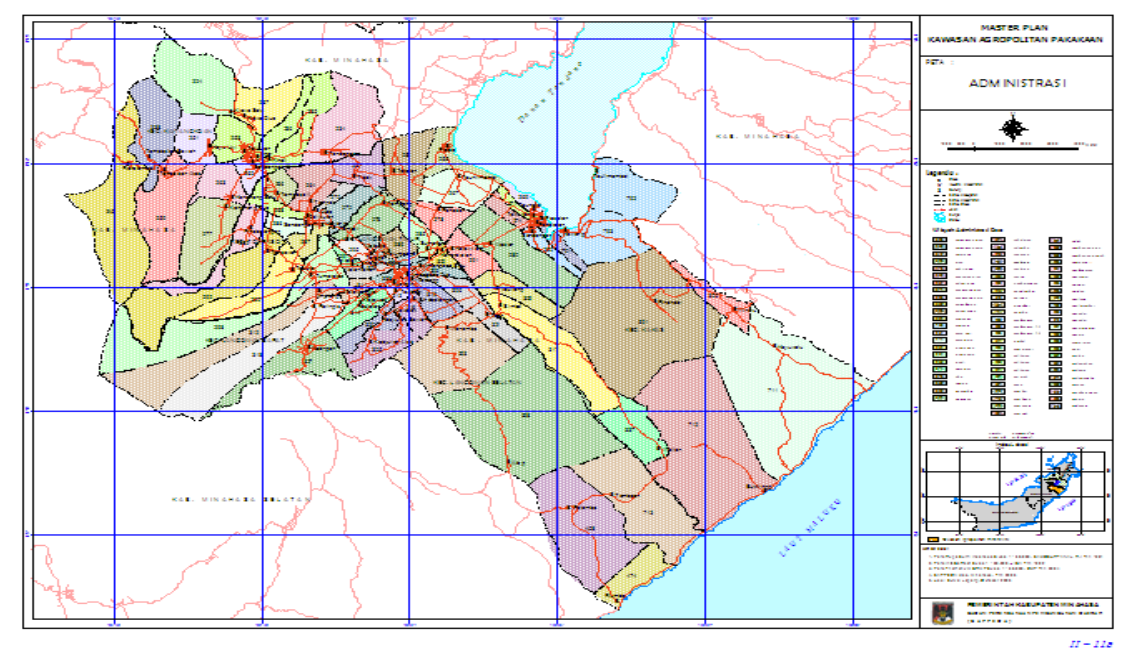

Gambar 1. Peta Kawasan PAKAKAAN 
Tabel 1. Potensi ketersediaan Rumput Pakan Sapi setiap Kecamatan di Kawasan PAKAKAAN

\begin{tabular}{|c|c|c|c|c|c|c|c|c|}
\hline \multirow[t]{2}{*}{ No } & \multirow[t]{2}{*}{ Kecamatan } & \multicolumn{6}{|c|}{ Produksi Hijauan (Rumput) Ton/Tahun } & \multirow[t]{2}{*}{ Jumlah } \\
\hline & & $\begin{array}{l}\text { Padang } \\
\text { Rumput }\end{array}$ & Sawah & $\begin{array}{c}\text { Galangan } \\
\text { Sawah }\end{array}$ & Perkebunan & Hutan & $\begin{array}{l}\text { Tegalan / } \\
\text { Ladang }\end{array}$ & \\
\hline 1 & Langowan Timur & 266 & 339 & 8 & 23 & - & 2 & 639 \\
\hline 2 & Langowan Barat & - & 261 & 7 & 28 & 351 & 7 & 653 \\
\hline 3 & Langowan Selatan & 1,369 & 169 & 4 & 286 & 71 & 71 & 1,971 \\
\hline 4 & Langowan Utara & - & 2,016 & 50 & 47 & - & 12 & 2,125 \\
\hline 5 & Tompaso & - & 661 & 17 & 148 & 96 & 11 & 932 \\
\hline 6 & Kawangkoan & - & 193 & 5 & 58 & - & 24 & 280 \\
\hline 7 & Kawangkoan Barat & - & 425 & 11 & 202 & 197 & 34 & 868 \\
\hline 8 & Kawangkoan Utara & - & 44 & 1 & 149 & 39 & 20 & 253 \\
\hline 9 & Kakas & 600 & 604 & 15 & 338 & 617 & 18 & 2,192 \\
\hline 10 & Kakas Barat & 209 & 591 & 15 & 698 & 94 & 21 & 1,628 \\
\hline & Jumlah & 2.444 & 5.302 & 133 & 1.977 & 1.464 & 221 & 11.541 \\
\hline
\end{tabular}

Sumber : Hasil Olahan

Potensi ketersediaan rumput sebagai pakan ternak sapi menurut kecamatan di Kawasan PAKAKAAN disajikan di Tabel 1.

Pada Tabel 1 di atas menunjukkan bahwa luas lahan sebesar 32.010 Ha akan dapat menghasilkan hijuan rumput ternak sapi sejumlah 11.541 ton/tahun. Lahan dengan produksi rumput terbesar yaitu area sawah dengan produksi 5.302 ton rumput per tahun. Padang rumput yang tersedia di Kawasan PAKAKAAN mampu menghasilkan sejumlah 2.444 ton rumput per tahun. Produksi rumput terkecil yaitu 133 ton per tahun diperoleh dari galangan sawah.

\section{Produksi Jerami}

Panen tanaman pangan menghasilkan produk sampingan berupa jerami. Jerami adalah hijauan limbah pertanian setelah biji dipanen dengan kadar serat kasar umumnya tinggi, bisa berasal dari rumput maupun legum (Tim Laboratorium Fapet IPB, 2012). Umumnya jerami tanaman tidak dimanfaatkan oleh petani karena setelah panen, jerami hanya dibiarkan atau dibakar. Padahal jerami dapat dimanfaatkan sebagai pakan ternak sapi. Jenis tanaman dan potensi jerami yang dapat dihasilkan menurut kecamatan di Kawasan PAKAKAAN dapat disajikan dalam Tabel 2 berikut ini. 
Tabel 2. Potensi Ketersediaan Pakan Jerami per Kecamatan di Kawasan PAKAKAAN Tahun 2013

\begin{tabular}{|c|c|c|c|c|c|c|c|c|c|}
\hline \multirow[t]{2}{*}{ No } & \multirow[t]{2}{*}{ Kecamatan } & \multicolumn{7}{|c|}{ Produksi Jerami (Ton) } & \multirow[t]{2}{*}{ Jumlah } \\
\hline & & $\begin{array}{c}\text { Padi } \\
\text { Sawah } \\
\text { (Ton) }\end{array}$ & $\begin{array}{c}\text { Padi } \\
\text { Ladang } \\
\text { (Ton) }\end{array}$ & $\begin{array}{c}\text { Jagung } \\
\text { (Ton) }\end{array}$ & $\begin{array}{c}\text { Kacang } \\
\text { Kadele } \\
\text { (Ton) }\end{array}$ & $\begin{array}{c}\text { Kacang } \\
\text { Tanah } \\
\text { (Ton) }\end{array}$ & $\begin{array}{c}\text { Ubi } \\
\text { Kayu } \\
\text { (Ton) }\end{array}$ & $\begin{array}{c}\text { Ubi } \\
\text { Jalar } \\
\text { (Ton) }\end{array}$ & \\
\hline 1 & Langowan Timur & 342 & - & 2,180 & - & - & 7 & 32 & 2,561 \\
\hline 2 & Langowan Barat & 137 & - & 10,355 & - & 19 & 13 & 16 & 10,540 \\
\hline 3 & Langowan Selatan & 63 & 6 & 6,616 & - & 19 & 2 & 23 & 6,729 \\
\hline 4 & Langowan Utara & 77 & 77 & 1,613 & - & 24 & 13 & 39 & 1,843 \\
\hline 5 & Tompaso & 290 & - & 24,089 & 101 & 72 & 10 & 14 & 24,576 \\
\hline 6 & Kawangkoan & 23 & - & 14,998 & 152 & 127 & 7 & 23 & 15,331 \\
\hline 7 & Kawangkoan Barat & 33 & - & 9,581 & - & 34 & 9 & 6 & 9,662 \\
\hline 8 & Kawangkoan Utara & 84 & - & 15,958 & 101 & 780 & 12 & 24 & 16,959 \\
\hline 9 & Kakas & 411 & 24 & 18,955 & - & 62 & 19 & 33 & 19,506 \\
\hline 10 & Kakas Barat & 332 & 5 & 15,707 & - & 41 & 48 & 105 & 16,238 \\
\hline & Jumlah & 1.791 & 112 & 120.053 & 354 & 1.178 & 140 & 315 & 123.943 \\
\hline
\end{tabular}

Sumber : Hasil Olahan

Pada Tabel 2 menunjukkan bahwa jumlah rataan jerami yang dapat dihasilkan yaitu sebesar 123.934 ton per tahun. Lahan untuk tanaman jagung memiliki potensi sebagai lahan penghasil jerami terbesar karena dapat menghasilkan sejumlah 120.053 ton jerami per tahun. Secara umum Kecamatan Tompaso berpotensi sebagai kecamatan dengan produksi jerami terbesar di Kawasan PAKAKAAN. Total produksi di kecamatan ini mencapai 24.576 ton per tahun.

Berdasarkan data jumlah ternak (dalam ST) dan data produksi pakan yang ada, baik rumput maupun jerami, dapat dirangkum data potensi ketersediaan pakan menurut kecamatan di Kawasan PAKAKAAN dalam Tabel 3 berikut ini.

Pada Tabel 3 menunjukkan bahwa potensi pakan yang dapat tersedia untuk 8.040 ST sapi di kawasan PAKAKAAN setiap tahunnya adalah sebesar 135.484 ton. Potensi ketersediaan pakan terbesar (91\%) yaitu pakan jerami yang jumlahnya mencapai 123.943 ton per tahun. Angka tersebut bahkan jauh lebih besar dari produksi rumput yang dapat dihasilkan. 
Tabel 3. Potensi Ketersediaan Pakan Sapi Per Kecamatan di Kawasan PAKAKAAN

\begin{tabular}{rlrrrrr}
\hline No & Kecamatan & $\begin{array}{c}\text { Sapi } \\
\text { Potong } \\
\text { (ST) }\end{array}$ & $\begin{array}{c}\text { Jerami } \\
\text { (ton/Thn) }\end{array}$ & $\begin{array}{c}\text { Rumput } \\
\text { (ton/Thn) }\end{array}$ & $\begin{array}{c}\text { Potensi } \\
\text { Pakan } \\
\text { (ton/Thn) }\end{array}$ & $\begin{array}{c}\text { Persen } \\
(\mathbf{\%})\end{array}$ \\
\hline 1 & Langowan Timur & 176 & 2.561 & 639 & 3.200 & 2,36 \\
2 & Langowan Barat & 776 & 10.540 & 653 & 11.193 & 8,26 \\
3 & Langowan Selatan & 312 & 6.729 & 1.971 & 8.700 & 6,42 \\
4 & Langowan Utara & 294 & 1.843 & 2.125 & 3.968 & 2,93 \\
5 & Tompaso & 1,428 & 24.576 & 932 & 25.508 & 18,83 \\
6 & Kawangkoan & 1,556 & 15.331 & 280 & 15.611 & 11,52 \\
7 & Kawangkoan Barat & 1,439 & 9.662 & 868 & 10.530 & 7,77 \\
8 & Kawangkoan Utara & 357 & 16.959 & 253 & 17.212 & 12,70 \\
9 & Kakas & 968 & 19.506 & 2.192 & 21.698 & 16,01 \\
10 & Kakas Barat & 735 & 16.238 & 1.628 & 17.866 & 13,19 \\
\hline & Jumlah & $\mathbf{8 . 0 4 0}$ & $\mathbf{1 2 3 . 9 4 3}$ & $\mathbf{1 1 . 5 4 1}$ & $\mathbf{1 3 5 . 4 8 4}$ & $\mathbf{1 0 0}$ \\
\hline Sumber : Hasil Olahan Data 2014 & & & &
\end{tabular}

\section{Indeks Daya Dukung (IDD)}

Indeks Daya Dukung (IDD) hijauan makanan ternak dihitung dari jumlah produksi hijauan makanan ternak yang tersedia terhadap jumlah kebutuhan hijauan bagi sejumlah populasi ternak ruminansia di suatu wilayah. Indeks daya dukung mencerminkan tingkat keamanan pakan pada suatu wilayah, untuk mendukung kehidupan ternak yang berada di atasnya. Jumlah penambahan sapi dan IDD untuk setiap kecamatan di Kawasan PAKAKAAN dapat disajikan dalam Tabel 4.

Berdasarkan Tabel 4, Kawasan PAKAKAAN memiliki populasi ternak sapi sejumlah 8.040 ST/tahun (Lampiran 1 dan 2). Kapasitas penambahan populasi ternak ruminansia dipengaruhi oleh luas lahan pertanian, luas panen dan populasi ternak ruminansia (Arfa'i dan Dirgahayu, 2007). Lahan yang ada di kawasan ini dapat menampung ternak sejumlah $118.846 \mathrm{ST} /$ tahun. Berdasarkan kapasitas tampung, penambahan ternak sapi dapat mencapai 108.740 ton per tahun. Penelitian mengenai kapasitas tampung lahan juga dilakukan oleh Wiyatna et.al. (2012) di Kabupaten Sumedang. Dalam penelitian tersebut diketahui bahwa di Kabupaten Sumedang perlu dilakukan 
Tabel 4. Kapasitas Penambahan Sapi dan Indeks Daya Dukung (IDD) per Kecamatan di Kawasan Pakakan

\begin{tabular}{rlrrrrrr}
\hline No & Kecamatan & $\begin{array}{c}\text { Sapi } \\
\text { Potong }\end{array}$ & $\begin{array}{c}\text { Potensi } \\
\text { Pakan }\end{array}$ & $\begin{array}{c}\text { Jumlah } \\
\text { Kebutuhan } \\
\text { Pakan }\end{array}$ & $\begin{array}{c}\text { Kapasitas } \\
\text { tampung }\end{array}$ & $\begin{array}{c}\text { Kapasitas } \\
\text { Penambahan } \\
\text { Sapi }\end{array}$ & $\begin{array}{c}\text { Indeks } \\
\text { Daya } \\
\text { Dukung } \\
\text { (IDD) }\end{array}$ \\
& (ST) & (ton/Thn) & (ton/Thn) & (ST/Thn) & (ST/Thn) & \\
\hline 1 & Langowan Timur & 176 & 3,200 & 200 & 2,807 & 2,631 & 16 \\
2 & Langowan Barat & 776 & 11,193 & 885 & 9,818 & 9,042 & 13 \\
3 & Langowan Selatan & 312 & 8,700 & 355 & 7,631 & 7,320 & 24 \\
4 & Langowan Utara & 294 & 3,968 & 335 & 3,481 & 3,187 & 12 \\
5 & Tompaso & 1,428 & 25,508 & 3,984 & 22,375 & 18,881 & 6 \\
6 & Kawangkoan & 1,556 & 15,611 & 1,774 & 13,694 & 12,138 & 9 \\
7 & Kawangkoan Barat & 1,439 & 10,530 & 1,640 & 9,237 & 7,798 & 6 \\
8 & Kawangkoan Utara & 357 & 17,212 & 407 & 15,098 & 14,741 & 42 \\
9 & Kakas & 968 & 21,698 & 1,104 & 19,033 & 18,065 & 20 \\
10 & Kakas Barat & 735 & 17,866 & 838 & 15,672 & 14,937 & 21 \\
\hline \multicolumn{1}{c}{ Jumlah } & $\mathbf{8 , 0 4 0}$ & $\mathbf{1 3 5 , 4 8 4}$ & $\mathbf{1 1 , 5 2 1}$ & $\mathbf{1 1 8 , 8 4 6}$ & $\mathbf{1 0 8 , 7 4 0}$ & $\mathbf{1 2}$ \\
\hline
\end{tabular}

Sumber : Hasil Olah Data

penambahan sapi sejumlah 86.017

ST. Adanya perbedaan kapasitas tampung dapat disebabkan oleh adanya perbedaan potensi produksi pakan di setiap daerah.

Jumlah kebutuhan pakan untuk 8.040 ST sapi per tahun berdasarkan Tabel 4 yaitu 11.521 ton/tahun. Berdasarkan ketersediaan lahan, potensi pakan dapat mencapai 135.484 ton/ tahun. Rataan indeks daya dukung lahan yang diperoleh dalam penelitian ini yaitu 12 dengan kisaran 6-42. Nilai IDD yang demikian (> 2) menunjukkan bahwa kawasan ini aman atau memiliki daya dukung lahan yang baik.
Penelitian daya dukung hijauan juga dilakukan oleh Atmiyati (2001) di Kabupaten Sambas. Dalam penelitian tersebut diperoleh hasil nilai IDD Kabupaten Sambas yaitu 65 dengan potensi pakan sebesar 464.477 ton BK/tahun. Penelitian daya dukung hijauan lainnya juga dilakukan oleh Arsyad (2012) di Kabupaten Pohuwato dengan nilai IDD yang diperoleh sebesar 63,78. Dalam penelitian tersebut juga diperoleh penambahan ternak sapi dapat mencapai 1.577.088 ekor. 


\section{KESIMPULAN}

Berdasarkan penelitian dapat disimpulkan beberapa hal yaitu:

1. Dengan jumlah ternak sebesar $\quad 8.040 \quad$ ST, ketersediaan pakan di Kawasan PAKAKAAN mencapai 135.484 ton per tahun. Pakan yang tersedia dapat memenuhi kebutuhan 118.846 ST sehingga populasi ternak perlu ditingkatkan sejumlah 108.740 ST.

2. Dengan kriteria IDD > 2, daya dukung lahan di Kawasan PAKAKAAN berada dalam kriteria “aman".

\section{DAFTAR PUSTAKA}

Arfa'i dan E. Dirgahayu. 2007. Analisis Potensi Pengembangan Ternak Sapi Potong Melalui Pendekatan Ketersediaan Lahan dan Sumberdaya Peternak di Kabupaten Padang Periaman, Sumatera Barat. Laporan Penelitian Dosen Muda. Fakultas Peternakan Universitas Andalas, Padang.
Ashari, F., E. Juarini, Sumanto, B. Wibowo, Suratman, 1995. Pedoman Analisis Potensi Wilayah Penyebaran dan Pengembangan Peternakan. Balai Penelitian Ternak dan Direktorat Bina Penyebaran dan Pengembangan Peternakan. Jakarta.

Amiyati. 2001. Daya Dukung Hijauan Pakan Terhadap Pengembangan Ternak di Kabupaten Sambas. BPTP Bogor. Jawa Barat.

Dinas Pertanian Kabupaten Minahasa. 2014. Laporan Tahunan 2014. Kabupaten: Minahasa

Sajimin, I P. Kompiang, Supriyati, dan Lugiyo. 2000. Pengaruh pemberian berbagai cara dan dosis Bacillus sp. terhadap produktivitas dan kualitas rumput Panicum maximum. hlm 359- 365. Prosiding Seminar Nasional Peternakan dan Veteriner. Pusat Penelitian dan Pengembangan Peternakan, Bogor.

Sumanto. E dan Juarini, 2006. Potensi Kesesuaian Lahan untuk Pengembangan Ternak Ruminansia di Provinsi Nusa Tenggara Timur. Prosiding Seminar Nasional Teknologi Peternakan dan Veteriner, Iptek Sebagai Motor Penggerak Pembangunan Sistem dan Usaha Agribisnis Peternakan. Bogor 4-5 
Agustus 2004. Wiyatna, M.F. Fuah dan K Puslitbangnak, Balitbangtan. Mudikdjo. 2012. Potensi Bogor. $\quad$ Pengembangan Usaha Sapi Tim Laboratorium Ilmu dan Potong Berbasis Sumber daya Teknologi Pakan Fapet IPB. 2012. Pengetahuan Bahan Makanan Ternak. CV Nutri Sejahtera, Bogor. Lokal di Kabupaten Sumedang Jawa Barat. Jurnal Ilmu Ternak Vol. 12 (2):1621. 